\title{
LOS MÁS RELEVANTES PROBLEMAS POLÍTICO-ELEGTORALES EN BRASIL (EL SISTEMA PROPORCIONAL) Y LA LUCHA CONTRA LA CORRUPGIÓN: DEL MENSALÃO A LA OPERACIÓN "LAVA-JATO"*
}

\author{
Marcelo FigueIREDO**
}

\begin{abstract}
SUMARIO: I. Introducción. II. El sistema electoral brasileño: la representación proporcional. III. La necesidad de la cláusula de desempeño. IV. El sistema proporcional brasileño: ¿proporcionalidad partidaria o personal? V. La infidelidad partidaria. VI. El Mensalão. VII. La operación "Lava-Fato". VIII. Conclusiones. IX. Bibliografia.
\end{abstract}

\section{INTRODUCGIÓN}

Esta intervención presentará un análisis sobre el funcionamiento constitucional de los partidos políticos en Brasil, así como su régimen jurídico fundamental. En Brasil tenemos la existencia de una pluralidad de sistemas electorales que combinan aspectos del sistema proporcional y del mayoritario. Algunas cuestiones vividas tanto en Italia como en Brasil son semejantes. Tanto el pueblo italiano como el brasileño no conocen bien lo que distingue un partido político del otro (en Brasil, actualmente, tenemos numerosos partidos políticos registrados en la justicia electoral, algunos con poca o casi nula representatividad).

A pesar de numerosas e importantes propuestas en materia electoral, el Congreso Nacional de Brasil ha aprobado solamente dos, la cláusula de

* Artículo recibido el 10 de noviembre de 2017 y aceptado para su publicación el 7 de diciembre de 2017.

Estas reflexiones fueron presentadas inicialmente en la mesa de discusión L'operazione "Lava-Fato" (La Mani Pulite brasiliana.') Cambiamenti di Comportamento e Contrasto Effetivo alla Corruzione, organizada por el professor Alessandro Sterpa el 4 de octubre de 2017.

** ORCID: 0000-0002-0231-2476. Abogado y consultor jurídico en São Paulo, Brasil. Profesor asociado de derecho constitucional de la Pontificia Universidad Católica de São Paulo (PUG-SP), correo electrónico:mfigueiredo@mfaa.com.br.

Boletín Mexicano de Derecho Comparado, nueva serie, año XLX, núm. 152, mayo-agosto de 2018, pp. 767-785.

Esta obra está bajo una Licencia Creative Commons Atribución-NoComercial-SinDerivar 4.0 Internacional, IIJ-UNAM. 
barrera y el fin de las coligaciones, y aun así, la segunda entrará en vigor hasta 2020. Ello demuestra el gran desprecio del Congreso por la voluntad de la mayoría del pueblo brasileño, pues dichas propuestas son apenas una gota en el océano si se comparan con la voluntad del pueblo, que desea una amplia reestructuración en el modelo político brasileño - lo que no ha sucedido hasta el momento-.

\section{EL SISTEMA ELECTORAL BRASILEÑO: LA REPRESENTACIÓN PROPORCIONAL}

La Asamblea Nacional Constituyente (1987-1988) elaboró una nueva Constitución de Brasil en 1988, vigente hasta hoy con 97 enmiendas. ${ }^{1}$ En el aspecto político-electoral, dicha Constitución mantuvo la justicia electoral (1932), su estructura, su funcionamiento y su rol de gran gestor de las elecciones en Brasil.

La federación brasileña se compone de la Unión, los estados, el Distrito Federal y los municipios. La Constitución establece reglas que alcanzan todos los asuntos que se presentan en todas estas entidades.

Para algunos estudiosos brasileños, como Figueiredo y Limongi, en algunos países, "elementos constitucionales", como la combinación de presidencialismo con representación proporcional y el multi-partidarismo, han estimulado el radicalismo, la indisciplina partidaria y el distanciamiento de la voluntad de los electores en la acción parlamentaria.

Es preciso recordar también que la Constitución de 1988, a pesar de (ser) reputada como democrática, ha mantenido algunos instrumentos introducidos por los militares, con miras a garantizar la preponderancia del Ejecutivo sobre el Legislativo y una mayor celeridad por parte de este último en el examen de las propuestas del primero. Entre ellos, resaltaremos la iniciativa legislativa exclusiva de ciertas leyes, la atribución del carácter de urgencia por el presidente de la República a los proyectos de su autoría y la emisión, por parte del jefe del Poder Ejecutivo, de medidas provisionales con fuerza de ley.

1 La enmienda constitucional núm. 97, del 4 de octubre de 2017, prohíbe coligaciones partidarias en las elecciones proporcionales, establece normas sobre el acceso de los partidos políticos a los recursos del fondo partidario y al tempo disponible para la propaganda gratuita en radio y televisión, y dispone sobre reglas de transición. Veremos, a lo largo del texto que, a pesar de la denominada "reforma política", el pueblo brasileño se ha quedado muy frustrado porque esperaba mucho más.

Esta obra está bajo una Licencia Creative Commons

Atribución-NoComercial-SinDerivar 4.0 Internacional, IIJ-UNAM.

Boletín Mexicano de Derecho Comparado, núm. 152, pp. 767-785. 
El artículo 45 de la Constitución federal reconoce la organización de los poderes y regula al Poder Legislativo y al Congreso nacional: "La Cámara de los Diputados se compone de los representantes del pueblo, elegidos por el sistema proporcional, en cada Estado, en cada Territorio y en el Distrito Federal". Los diputados federales y estatales, así como los ediles o concejales, dado el principio federativo, son elegidos por el sistema proporcional de representación, regulado por los artículos 106 a 110 del código electoral brasileño. El sistema se caracteriza por el voto personal, único, en candidatura individual, sin propuesta de listas, pero sí de varias candidaturas individuales entre las cuales el elector selecciona sólo una.

Los votos destinados a los candidatos de un mismo partido definen el cociente partidario, y los votos que exceden al cociente electoral de los que ya están elegidos y de los candidatos que no han logrado el cociente electoral se transfieren a los del mismo partido o coligación.

En el sistema vigente, el elector brasileño, al votar por determinado candidato en las elecciones proporcionales, en realidad, manda el mensaje a la justicia electoral de que desea, en suma, ser representado por el partido o coligación que ha elegido, precisamente por el candidato que él ha indicado; si acaso su candidato no resultara electo o no hubiera obtenido votos suficientes para ello, la justicia electoral está autorizada a transferir su voto al candidato del mismo partido o coligación que esté más cerca de la victoria.

Según José Antonio Giusti Tavares, la fórmula destinada a la atribución del cociente electoral prevista en el código electoral brasileño (artículo 106) fue concebida por el matemático Carl Christoffer Georg Andræ, en 1855, para regular las elecciones de la Cámara Alta de Dinamarca. Más tarde, en 1957, el inglés Thomas Hare, incorporando la idea de Andræ, asoció la concepción del cociente electoral al voto único a la llamada cuota Hare. Brasil adopta, por tanto, la llamada fórmula d'Hondt de mayores promedios.

Podemos decir que, en general, la acción de los diputados federales en las últimas legislaturas, en el sistema que combina el presidencialismo con el de la representación proporcional de lista abierta, ${ }^{2}$ ha ejercido una influencia considerable sobre el comportamiento parlamentar.

2 La cuestión de la lista abierta a cerrada plantea una dicotomía, como muy bien observa Fernando Limongi: "Quem adota a primeira (aberta) modalidade de representação 
Las reglas políticas vigentes han concurrido junto con otros factores, notoriamente culturales, para formar una multiplicidad de partidos débiles, ${ }^{3}$ con poca capilaridad social, identidad ideológico-programática y cohesión. Estas asociaciones, en general, están constituidas por políticos individualistas, particularistas y personalistas y cuentan con un largo histórico de migración partidaria. La fragilidad, el pragmatismo y la incongruencia de los partidos, así como el individualismo, el particularismo y el apartidismo de los integrantes de sus bancas congresistas son de tal magnitud que el gobierno, en cada votación importante, precisa negociar con su base de sustentación muchas veces en un plano individual.

El primero afirma que nuestro sistema no garantiza la gobernabilidad de calidad. La manera como se integra la mayoría, dada la pulverización partidaria, es de baja calidad y muy susceptible a los cambios de humor repentinos del Congreso y de los grupos de presión. Cada votación requiere una nueva negociación. Lograr la participación de los partidos en los ministerios, en el gobierno, no garantiza nada. Esto es una tragedia.

El segundo entiende que, como no hay partido y la persona no se elige por una lista partidaria cerrada, resulta muy difícil conseguir aglutinación. Aunque el partido decida alguna cosa, la persona vota como quiere. No se siente responsable ante el partido. No se siente responsable ante el

proporcional a vê como causa do individualismo, da corrupção e da falta de accontability; acredita que tudo isso será minorado ou solucionado com a mudança para a lista fechada. Mas quem adota a segunda versão (lista fechada) quer migrar para a primeira, porque acredita que a lista fechada dá razões para que as lideranças políticas se isolem das demandas populares, etc. Obviamente não é possível que ambos estejam corretos. Cada uma dessas opções tem seus prós e contras. Pode ser verdade que uma seja melhor que a outra, mas o fato é que nenhuma delas trará a solução para todos os problemas identificados. E não importa, ou melhor, não é isto que importa se quisermos entender o apelo da retórica da reforma política". En español: "Quien adopta la primera (abierta) modalidad de representación proporcional la ve como causa del individualismo, de la corrupción de la falta de accontability; cree que todo eso será aminorado o solucionado con el cambio a la lista cerrada. Pero quien adopta la segunda versión (lista cerrada) quiere emigrar hacia la primera, porque cree que la lista cerrada da motivos para que los liderazgos políticos se aíslen de las demandas populares, etc. Obviamente no es posible que ambos estén correctos. Cada opción tiene sus pros y sus contras. Puede ser verdad que una sea mejor que la otra, pero el hecho es que ninguna de ellas ofrecerá la solución a todos los problemas identificados. Y no importa, o mejor, no es eso lo que importa si queremos entender el postulado de la retórica de la reforma política". Cfr. Limongi, Fernando, "Reforma política: o longo debate", Revista Parlamento e Sociedade, São Paulo, vol. 3, núm. 4, 2015, p. 13.

3 Brasil en 2014 tenía 32 partidos políticos registrados. Hoy tiene 35.

Esta obra está bajo una Licencia Creative Commons

Atribución-NoComercial-SinDerivar 4.0 Internacional, IIJ-UNAM.

Boletín Mexicano de Derecho Comparado, núm. 152, pp. 767-785. 
gobierno. Si él es religioso, vota de acuerdo con su religión. Si representa una corporación, vota con su corporación. No hay cohesión.

\section{LA NECESIDAD DE LA CLÁUSULA DE DESEMPEÑO}

De los 35 partidos que existen hoy, se estima que aproximadamente ocho comparten alguna especie de "ideología", al menos si nos atenemos a los términos y conceptos empleados en sus estatutos de constitución.

Ocho de ellos se autodenominan "laboristas", siete "socialistas" o "comunistas", dos "ecologistas", y los demás se dividen apenas en dos o tres ideologías declaradas como "cristiana", "republicana" y "humanista".

Todos se preguntan: si hay, cuando mucho, siete u ocho partidos con corrientes ideológicas, ¿para qué necesitamos 35 leyendas diversas?

El exceso irracional de partidos políticos sirve apenas para crear inestabilidad en el sistema político-electoral, perjudicando las opciones legítimas del electorado y, en definitiva, la propia gobernabilidad. Es impracticable hilvanar un acuerdo con por lo menos 20 bancas de diferentes partidos políticos en el sistema brasileño. No se puede imputar el número excesivo de partidos políticos registrados en Brasil a la gran heterogeneidad social, pero sí a las imperfecciones del sistema electoral y político adoptado en el país.

Lamentablemente, la población brasileña tiene la percepción clara de que los partidos políticos vienen siendo utilizados como simples instrumentos de defensa de los intereses de sus dirigentes en detrimento de su noble función constitucional. Por ello no es de extrañar que el resultado de las urnas en el sistema proporcional refleje la manipulación partidaria y no la voluntad popular.

Los partidos son utilizados como "mera" moneda de cambio en alianzas, coligaciones y aumentos del tiempo disponible de propaganda electoral gratuita, en radio y televisión. En fin, las leyendas partidarias los revelan como verdaderos "vientres de alquiler" para ofrecer ventajas a sus dirigentes inescrupulosos que, incluso, perciben beneficios de los fondos partidarios públicos.

La fragilidad del sistema político-electoral brasileño se debe, así, en gran parte, a la composición de las casas legislativas que giran alrededor de las personas de los candidatos y no de los partidos políticos, hoy en su mayoría sin un contenido ideológico bien definido y con un contenido pro- 
gramático superficial y variable, al albedrío de los intereses del momento. Es evidente el debilitamiento de los partidos políticos en este escenario.

La existencia de un número grande de partidos dificulta la fiscalización de la actuación de las agremiaciones, conduce al nacimiento de partidos desprovistos de ideología política y propicia la venta de votos dentro del Legislativo, hechos que afectan el funcionamiento de la propia democracia.

Todos sabemos que no existe un sistema electoral perfecto. Cada sistema presenta ventajas y desventajas o, si quisiéramos, virtudes y deficiencias, como ya lo ha demostrado la experiencia internacional. Esto propicia el surgimiento de los sistemas mixtos, construidos a partir de elementos extraídos de las dos categorías. Pero ambas conllevan aspectos positivos y negativos.

\section{EL SISTEMA PROPORGIONAL BRASILEÑO: ¿PROPORCIONALIDAD PARTIDARIA O PERSONAL?}

El sistema electoral proporcional está vigente en Brasil desde hace casi un siglo. Tenemos un modelo proporcional peculiar, diferente del modelo proporcional tradicional, que se asienta en listas presentadas por los partidos políticos.

La lista abierta de candidatos existente en el país hace que el mandato parlamentar que resulta de este sistema se configure también más como fruto del desempeño y del esfuerzo del candidato que de la actividad partidaria, de manera similar a como acontece en Finlandia.

José de Alencar ya enseñó hace más de cien años que la buena representación política debe evitar dos extremos: la aplanadora de la mayoría sobre la minoría y el veto paralizante de ésta sobre la primera.

En este tema existen muchas divergencias. Es innegable y evidente el fuerte desequilibrio electoral en la Federación brasileña, donde, por ejemplo, la población de São Paulo, en vista del piso constitucional (8 diputados por lo menos por estado y 70, como máximo), no encuentra la proporción adecuada. São Paulo, el estado más poblado de Brasil, está subrepresentado en la Cámara de Diputados en por lo menos un 14\%.

Hay cierto consenso doctrinario en el sentido de que impera en Brasil alguna irracionalidad respecto a los arreglos institucionales de la proporcionalidad electoral. $\mathrm{O}$, en otras palabras, la indefinición sobre el aspecto

Esta obra está bajo una Licencia Creative Commons

Atribución-NoComercial-SinDerivar 4.0 Internacional, IIJ-UNAM.

Boletín Mexicano de Derecho Comparado, núm. 152, pp. 767-785. 
prioritario de la proporcionalidad conduce a la indagación de que haya o no que asegurar la proporcionalidad de los votos en términos partidarios o personales (nominal).

En Brasil, el sistema proporcional tiene las siguientes características: a) lista abierta; $b$ ) voto uninominal; $c$ ) posibilidad de voto de leyenda o nominal; $d$ ) formación de coligaciones, sin federación de partido y sin obligatoriedad de verticalización; e) lista única de candidatos, incluso cuando hay coligación, con ausencia de cociente intra-coligación, y $f$ ) exigencia de votación nominal mínima.

En síntesis, queda mucho por perfeccionar en el sistema proporcional brasileño vigente. Es preciso acortar las distancias entre el representante y el representado, incluso para posibilitar al elector y a la sociedad, por medio de sus organismos controladores, que haga valer la responsabilidad política del electo, marca de los sistemas democráticos.

La calidad del proceso democrático debe ser una preocupación constante en nuestra región. Después de los periodos de dictadura, hemos pasado a tener elecciones periódicas, pero todavía estamos lejos de tener a disposición mecanismos eficaces de atribución de responsabilidad de los candidatos electos.

Las coligaciones partidarias también se deben reformular y perfeccionar, así como el reparto de las vacantes logradas por la coligación entre los partidos que la componen. Los partidos políticos deben asumir y, en lo posible, rescatar su protagonismo al regular las coligaciones, de modo que se alcance alguna coherencia que tenga sentido para el elector. ${ }^{4}$

\section{LA INFIDELIDAD PARTIDARIA}

La Constitución de 1988, de rasgos más democráticos, ha dejado este tema reservado a la discreción interna de los partidos (artículo 17, §1o.). Es raro que un partido expulse a un candidato por infidelidad partidaria, y a pesar de que la Ley núm. 9.096/1995, en sus artículos 23 a 26, dispone sobre esta materia, al regular la pérdida del cargo o función, el legislador utiliza los términos "casa legislativa" "proporción partidaria" y "parlamentaria", al referirse al sistema proporcional y no al mayoritario.

4 Entre las reformas en debate, todo indica que las coaliciones partidarias no serán permitidas en lo sucesivo a partir del año 2020.

Esta obra está bajo una Licencia Creative Commons Atribución-NoComercial-SinDerivar 4.0 Internacional, IIJ-UNAM. Boletín Mexicano de Derecho Comparado, núm. 152, pp. 767-785. 
La construcción jurisprudencial de la tesis de la pérdida del mandato electivo por infidelidad partidaria comenzó en 2007, cuando el Tribunal Superior Electoral, en respuesta a la consulta del TSE núm. 1.398, adoptó una nueva interpretación del texto constitucional, afirmando que el mandato pertenece al partido político y no al parlamentar electo por el sistema proporcional.

El Tribunal Superior Electoral, en una decisión polémica, ${ }^{5}$ editó la Resolución núm. 22.610/2007 ${ }^{6}$ permitiendo la retención de las vacantes de los partidos políticos en las casas parlamentares. Si el parlamentario abandona un partido para filiarse a otro, sin justa causa, perderá su mandato, al final de la acción de competencia de la justicia electoral. ${ }^{7}$

Decretada la pérdida del mandato mediante el procedimiento competente ante la justicia electoral, la vacante será ocupada por el suplente más graduado, aunque éste no sea del mismo partido que su antiguo ocupante. Si el partido se coaligó para disputar las elecciones, la suplencia se forma de acuerdo con los votos que ha obtenido la coalición.

En el sistema brasileño, el elector, como hemos visto, ejerce plenamente su derecho al voto, pero su libertad de elección se limita a los candidatos elegidos por el partido para las elecciones, ya que hasta el momento no se admite la candidatura aislada.

La infidelidad partidaria es uno de los importantes factores que contribuyen al individualismo en las elecciones y la política brasileña. Las migraciones constantes de parlamentares enseguida de las elecciones, movidos por intereses egoístas o personalísimos (políticos), contribuyen para aumentar el descrédito en los sistemas político y electoral brasileños, des-

5 Algunos sostienen la necesidad de una enmienda constitucional para lograr tal efecto y critican, con razón, el efecto retroactivo de la Resolución. De cualquier forma, la norma no ha sido juzgada inconstitucional por el Supremo Tribunal Federal.

6 Según la Resolución del TSE núm. 22.526, del 8 de mayo de 2007, el mandato del diputado elegido por el sistema proporcional pertenece al partido que lo eligió y no a la persona del diputado. Por ello, el diputado que haya cambiado de partido queda sujeto a la pérdida de mandato.

7 Dicha Resolución ha tenido varias críticas de la doctrina constitucional al regular la pérdida de mandato electivo, incluso ante la falta de previsión constitucional expresa que lo autorizara, excediendo, para muchos, cualquiera facultad normativa. Sobre el tema: Clève, Clèmerson Merlin e Clève, Ana Carolina de Camargo, "A evolução da fidelidade partidária na jurisprudência do Supremo Tribunal Federal", Direito eleitoral contemporâneo, Livro especial.

Esta obra está bajo una Licencia Creative Commons

Atribución-NoComercial-SinDerivar 4.0 Internacional, IIJ-UNAM.

Boletín Mexicano de Derecho Comparado, núm. 152, pp. 767-785. 
acreditando, en consecuencia, a los partidos políticos y desmoralizando a los mandatarios en general.

La sanción de la pérdida del mandato electivo parece ser una respuesta adecuada a la infidelidad partidaria, puesto que les cuesta la pérdida del mandato a aquellos que abandonan sus partidos sin motivo justificado.

\section{EL MENSALÃO}

El Mensalão seguramente es uno de los mayores esquemas de corrupción en la historia de Brasil. Involucra a miembros del Congreso Nacional, partidos políticos, dirigentes de órganos de la administración pública federal directa e indirecta, instituciones financieras y empresas privadas.

El nombre Mensalão (gran mesada) deriva de entregas periódicas (algunas de ellas realizadas mes a mes) de recursos obtenidos de forma ilícita a parlamentares y a partidos políticos a cambio de apoyo a las propuestas y postulaciones del gobierno en el Congreso Nacional.

Se constató que de la indicación político-partidaria para la ocupación de cargos de comando en diversos organismos y entidades de la administración pública federal resultaba la captación indebida de recursos públicos mediante la sobrefacturación de precios en las contrataciones, el pago de propina y otros medios espurios. Los recursos captados se destinaban a financiar campañas electorales, a atraer parlamentares y partidos a la base de apoyo del gobierno en el Congreso nacional y a enriquecer ilícitamente a agentes públicos, políticos, empresarios y demás participantes del esquema.

Según Lucas Rocha Furtado, los recursos que alimentaban el esquema del Mensalão provenían, en gran parte, de los contratos administrativos celebrados por diversos órganos y entidades de la administración pública federal con las empresas de publicidad DNA Propaganda Ltda. y SMP\&B Comunicações Ltda., vinculadas al empresario Marcos Valerio Fernandes de Souza.

De la misma manera, habiendo resultado vencedor en las elecciones presidenciales, el Partido de los Trabajadores (PT), buscando, entre otros objetivos, negociar apoyo político con parlamentares y otros partidos y pagar los gastos de la campaña electoral, se aproximó a Marcos Valerio, a los efectos de que el empresario publicitario implantara, en la esfera federal, el mismo esquema operado en Minas Gerais. 
En los contratos firmados entre las empresas de publicidad de Marcos Valerio y el gobierno federal se constataron diversas irregularidades: evasión fiscal, mantenimiento de contabilidad paralela, emisión de facturas falsas para justificar costos en la prestación de los servicios, entre otras. Todas esas irregularidades estaban relacionadas con el mecanismo de recaudación ilegal de fondos para financiar el esquema de corrupción.

Los hechos se hicieron públicos a partir de la divulgación, por la prensa, de la existencia de un video grabado en el cual el exdirector de la Dirección General de Correos fue sorprendido solicitando una ventaja indebida para beneficiar empresarios interesados en participar en el rol de proveedores de la estatal.

Además de sucesivos fallos condenatorios de la justicia en Brasil que involucraban a los inculpados ${ }^{8}$ por estos esquemas, fueron propuestas varias modificaciones a la normativa con el propósito de evitar que volvieran a ocurrir semejantes problemas e ilegalidades. Entre dichas propuestas se destacan las modificaciones a la Ley de Probidad Administrativa, reducción de la discrecionalidad en las licitaciones públicas, institución del programa de incentivo a revelaciones de interés público, creación del Sistema Nacional de Combate a la Corrupción (SNGG), transformación del Consejo Nacional de Control de Actividades Financieras (COAF) en Agencia Nacional de Inteligencia Financiera (ANIF), reformulación del actual Sistema Brasileño de Protección a la Información Sigilosa [N. de la E.: Información Reservada], extinción del fuero que gozan distintas autoridades federales o estatales, extinción de la financiación privada de campañas políticas y mayor transparencia en la máquina pública.

Lamentablemente pocas de las medidas propuestas se han transformado en leyes o en medidas concretas. Otras han sido introducidas, sin embargo, buscando alterar esta realidad y combatir la corrupción. Por ejemplo:

1. El fuero privilegiado en el STF continúa existiendo en Brasil. Diputados y senadores tienen inmunidad formal y material y únicamente pueden ser presos en flagrante delito de crimen sin derecho a fianza. Además, su Casa podrá decidir sobre la prisión (artículo 53, §2o. de la Constitución federal).

8 Excepto los políticos con jurisdicción privilegiada, cuya atribución de responsabilidad se ha mostrado muy lenta.

Esta obra está bajo una Licencia Creative Commons

Atribución-NoComercial-SinDerivar 4.0 Internacional, IIJ-UNAM.

Boletín Mexicano de Derecho Comparado, núm. 152, pp. 767-785. 
Además de otros inconvenientes, el fuero, al contemplar el juzgamiento de los políticos y otras altas autoridades de la República en el Supremo Tribunal Federal, produce inconvenientes porque la Corte Suprema es un tribunal constitucional con centenas de miles de procesos y no tiene vocación para juzgar de manera originaria casos penales complejos que exigen instrucción procesal, ${ }^{9}$ ocurridos en los más variados estados de la Federación brasileña. La obtención de la prueba, los testimonios, en fin, toda la instrucción de un proceso penal, no es compatible con las funciones de una corte constitucional con sede en Brasilia, con 11 ministros. Todo ello sin mencionar el riesgo del advenimiento de la prescripción en varios procesos.

2. Se aprobó la extinción de la posibilidad de financiación privada en campañas políticas después de una enorme presión popular y de instituciones de combate a la corrupción, inclusive de la Orden de los Abogados de Brasil.

Hoy las donaciones de empresas están prohibidas, en gran parte debido a los últimos escándalos. La solución encontrada por el Congreso no ha sido del agrado de los brasileños porque creó una financiación pública millonaria en un país en recesión económica.

El proyecto - que prevé fondos de $\mathrm{R} \$ 4.400$ millones en la Ley Presupuestaria Anual de 2018 - aún depende de la sanción presidencial, pero todo indica que será aprobado. ${ }^{10}$

Preocupa, todavía en el proyecto, la previsión que permite a los jefes partidarios decidir cómo será distribuido el dinero entre los candidatos,

9 Mientras que la Suprema Corte norteamericana juzga cien casos por año, la nuestra juzga cien mil.

10 El Plenario de la Cámara de Diputados aprobó el 4 de octubre de 2017 la creación de un fondo público más para financiar candidatos. La propuesta está en curso para sanción del presidente de la República. En caso de ser sancionada, en 2018 cerca de R $\$ 2.000$ millones de recursos públicos serán destinados a los partidos. En la propuesta también consta el fin de la propaganda partidaria (no la electoral) en televisión y radio. Siempre ha sido ésa la intención del legislativo, sobre todo después de la decisión del Supremo Tribunal Federal que prohibió, en 2015, que las empresas continuaran financiando a los partidos, y como consecuencia, a los candidatos. Entre las modificaciones propuestas están la liberación de la propaganda pagada en la Internet, el telemarketing electoral y algunos cambios en las reglas de debates electorales en la TV, además de una amnistía de multas ya aplicadas a partidos políticos por la justicia electoral.

Esta obra está bajo una Licencia Creative Commons Atribución-NoComercial-SinDerivar 4.0 Internacional, IIJ-UNAM. Boletín Mexicano de Derecho Comparado, núm. 152, pp. 767-785. 
fortaleciendo lo que se ha llamado "caciquismo político". ${ }^{11}$ Los líderes y políticos más fuertes recibirían más fondos que los candidatos con menos fuerza y penetración en el medio político.

3. Modificaciones puntuales a la Ley de (Im)probidad Administrativa (Ley núm. 8.429/1992) y la institución de la Ley de la Ficha Limpia (Ley Complementaria núm. 135/2010).

En síntesis, las hipótesis de inelegibilidad que trajo la Ley de la Ficha Limpia son las siguientes: a) condenas judiciales (electorales, penales, o por improbidad administrativa, dictadas por un órgano colegiado; $b$ ) rechazo de las cuentas correspondientes al ejercicio del cargo o función pública (necesariamente colegiadas, por ser dictadas por el Legislativo o por el Tribunal de Cuentas, en su caso); c) pérdida del cargo (electivo o de ocupación efectiva), incluyendo las jubilaciones forzosas de magistrados y miembros del Ministerio Público y, para los militares, la indignidad o incompatibilidad con el rango; $d$ ) renuncia a un cargo público electivo ante la inminencia de la instauración de un proceso que pueda causar la pérdida del cargo, y e) exclusión del ejercicio de una profesión reglamentada, por decisión del órgano profesional respectivo, por violación de un deber ético-profesional.

\section{Aprobación de la Ley Anticorrupción (Ley num. 12.846/2013)}

En síntesis, esta norma permite sancionar con penas administrativas y civiles a una empresa considerada corruptora, obligándola, en la práctica, a indemnizar al poder público, además de autorizar, en casos extremos, su extinción forzada por orden judicial.

La ley, por tanto, adopta el mecanismo de la responsabilidad objetiva de la persona jurídica por los actos que atenten contra el patrimonio público, nacional o extranjero, contra principios de la administración pública o contra los compromisos internacionales asumidos por Brasil, practicados en su interés, independientemente de la comprobación de mala fe o negli-

11 Entre las propuestas recientemente aprobadas tenemos un límite de gastos en las campañas electorales. Hasta el año 2014, eran los partidos quienes definían sus gastos. En la propuesta aprobada que va a sanción o veto del presidente de la República, se establece un techo de 70 millones de reales para el candidato a presidente y 21 millones para los gobernadores, según el tamaño del estado.

Esta obra está bajo una Licencia Creative Commons

Atribución-NoComercial-SinDerivar 4.0 Internacional, IIJ-UNAM.

Boletín Mexicano de Derecho Comparado, núm. 152, pp. 767-785. 
gencia, de la responsabilidad individual de las personas naturales (dirigentes) o cualquier otra persona o partícipe del acto ilícito.

\section{La Ley de Delación (o colaboración) premiada y la Ley de las Or- ganizaciones Criminosas}

La delación premiada es un instituto de naturaleza penal, puesto que configura un factor de disminución de la reprimenda legal o del perdón judicial, causa extintiva de la punibilidad.

Siguiendo las tradiciones norteamericana e italiana en la materia, la delación premiada fue introducida tímidamente en la Ley núm. 8.072/1990, que trataba de los delitos "de bando o cuadrilla", posteriormente en la Ley núm. 8.137/1990 y, por fin, en la Ley núm. 9.080/1995, que disciplina los delitos contra el orden tributario y económico y establece otras providencias. Con posiciones divergentes en la doctrina brasileña, el instituto de la delación sigue como un poderoso instrumento de investigación.

Junto con él, o a su lado, tenemos también el Acuerdo de Lenidad, en parte inspirado en su homólogo norteamericano, el Leniency Program, aplicado primero en el ámbito del derecho de la competencia (Ley núm. 12.529/2011), y después en el ámbito penal y procesal penal (Ley núm. 12.846/2013).

Sobre el tema Nucci enseña:

...parece-nos que a delação premiada é um mal necessário, pois o bem maior a ser tutelado é o Estado Democrático de Direito. Não é preciso ressaltar que o crime organizado tem ampla penetração nas entranhas estatais e possui condições de desestabilizar qualquer democracia, sem que se possa combatêlo, com eficiência, desprezando-se a colaboração daqueles que conhecem o esquema e dispõem-se a denunciar coautores e partícipes. No universo de seres humanos de bem, sem dúvida, a traição é desventurada, mas não cremos que se possa dizer o mesmo ao transferirmos nossa análise para o âmbito do crime, por si só, desregrado, avesso à legalidade, contrário ao monopólio estatal de resolução de conflitos, regido por leis esdrúxulas e extremamente severas, totalmente distante dos valores regentes dos direitos humanos fundamentais. ${ }^{12}$

12 En español: “...nos parece que la delación premiada es un mal necesario, pues el bien mayor a tutelar es el Estado Democrático de Derecho. No es preciso resaltar que el crimen organizado tiene amplia penetración en las entrañas estatales y tiene condiciones de desestabilizar cualquier democracia, sin que se lo pueda combatir con eficiencia, des- 
Para nosotros, inmoral no es "negociar" con corruptos para desbaratar las cuadrillas y organizaciones criminosas, sino no desvendar crímenes que devastan el patrimonio público brasileño y mundial.

\section{LA OPERACIÓN "LAVA-JATO”}

El 17 de marzo de 2001 varios cambistas estaban siendo investigados por la policía federal y por el juez Sérgio Moro. El albo de la diligencia no era Petrobras, sino el dueño de un lavadero de autos localizado en una estación de servicio en Brasilia, de donde surgió el nombre de la operación "Lava-Jato".

Dos cambistas confesaron sus participaciones en múltiples crímenes y delataron a muchas personas, entre ellas, diversos políticos y empresarios, que también serían criminosos contumaces. De manera paralela, se descubrió que el sector político-empresarial estaba involucrado, a partir de delaciones recompensadas y del surgimiento de nuevas pruebas.

En rigor, no sólo en Petrobras, sino también en el Mensalão, el esquema de corrupción, de modo general, involucraba políticos, empresarios, agentes públicos y operadores financieros que actuaban cada cual, en su núcleo específico, de la siguiente manera:

a) El núcleo político formado por los partidos y por sus integrantes, principalmente parlamentares, quienes indicaban y mantenían funcionarios de alto escalón en la administración pública, percibiendo ventajas indebidas pagadas por las empresas componentes del núcleo económico;

b) El núcleo económico, formado por las empresas del cartel que eran contratadas por la administración pública y que pagaban ventajas indebidas a algunos funcionarios de alto escalón y componentes del núcleo político;

preciándose la colaboración de aquellos que conocen el esquema y se disponen a denunciar coautores y partícipes. En el universo de seres humanos de bien, sin duda, la traición es desventurada, pero no creemos que se pueda decir lo mismo al transferir nuestro análisis al ámbito del crimen, por sí sólo desreglado, opuesto a la legalidad, contrario al monopolio estatal de resolución de conflictos, regido por leyes esdrújulas y extremadamente severas, totalmente distante de los valores regentes de los derechos humanos fundamentales". Cfr. Nucci, Guilherme de Souza, Princípios Constitucionais Penais e Processuais Penais, 3a. ed., São Paulo, 2013, p. 50.

Esta obra está bajo una Licencia Creative Commons

Atribución-NoComercial-SinDerivar 4.0 Internacional, IIJ-UNAM.

Boletín Mexicano de Derecho Comparado, núm. 152, pp. 767-785. 
c) El núcleo administrativo, formado por los funcionarios de alto escalón de la administración pública, quienes eran indicados por los integrantes del núcleo político y percibían ventajas indebidas de las empresas del cartel que integraban el núcleo económico, y

d) El núcleo financiero, formado por los operadores tanto de la recepción de las ventajas indebidas provenientes de las empresas del cartel del núcleo económico, como de la distribución de la propina a los componentes de los núcleos político y administrativo, mediante estrategias de ocultación del origen de esos valores. ${ }^{13}$

Hoy, la operación "Lava-Jato" revela números impresionantes. ${ }^{14} \mathrm{El}$ importe de las propinas que se pagaron asciende a aproximadamente $\$ 6,400$ millones de reales brasileños. La recuperación del dinero desviado ya llega a $\$ 10,000$ millones de reales, fruto de acuerdos de colaboración premiada y de delaciones premiadas. Hasta diciembre de 2016, ya había 24 sentencias condenatorias contra más de 120 personas, con 1,300 años de penas de prisión. Incluso los más escépticos y desconfiados se rinden a los méritos de la "Lava-Jato", que aún es criticada por no haber alcanzado a todos los partidos políticos de varias ideologías. La operación "Lava-Jato" 15 también tiene el mérito de haber expuesto la

13 La actuación del núcleo económico era intrínsecamente dependiente de la actuación del núcleo político, puesto que éste era el encargado de indicar y mantener un núcleo administrativo en los organismos públicos contratantes volcados hacia la realización de los intereses ilícitos. El núcleo económico pagaba ventajas ilícitas a los integrantes del núcleo político, sea para beneficiarse de las contrataciones públicas, sea para obtener protección política. (Proc. n.54347/2017-GTLJ-PGR-STF).

14 Y sigue adelante, no se sabe cuándo termina, pues se ha desdoblado en varias otras operaciones e investigaciones.

15 El reciente testimonio de un exministro de la Casa Civil, Antonio Palocci, de los gobiernos de Lula da Silva y Dilma Rousseff ha sido devastador en el ámbito de la "Lava-Jato". Atribuyó al expresidente Lula el comando del ataque a los cofres de Petrobras para viabilizar la sucesión de Dilma Rousseff. Adiciónese a ello la denuncia del procurador General de la República, colocando al actual presidente Temer en el centro de una organización criminosa, que opera en el campo de la venta de actos legislativos, contrataciones públicas y acceso a fondos de la comunidad, como el FAT, dan la dimensión de la degradación política a la que hemos llegado. Pero tiene razón Oscar Vilhena al analizar el presente cuadro político, cuando afirma: "Como era de se esperar, as reações de envolvidos, investigados e denunciados têm sido virulenta, questionando não apenas a integridade da operação, como também os seus eventuais benefícios para a sociedade. Moralista, seletiva, messiânica, persecutória e irresponsável são alguns dos adjetivos 
corrupción enraizada en el sistema político brasileño. ${ }^{16}$ Muchos le adjudican parte de los problemas al llamado presidencialismo de coalición. En dicho modelo, el presidente de la República, para gobernar, precisa montar una amplia base de apoyo parlamentario en el Congreso nacional.

atribuídos às operações. De fato, algumas ações dos agentes de aplicação da lei, como vazamentos, escutas ilegais, extensão desnecessária de prisões processuais, culminando com uma obscura participação de membro do Ministério Público no acordo de delação hiperpremiada de Joesley Batista, são intoleráveis. Por isso devem ser anuladas e os responsáveis devidamente punidos. Devemos, no entanto, tomar muito cuidado para «não jogar o bebê com a água do banho». O julgamento do Mensalão, assim como a Operação Lava-Jato, com todas as suas deficiências, está impondo, aos trancos e barrancos, um novo paradigma na condução dos negócios públicos no país. Sua natureza disruptiva vem colocando em xeque não apenas o padrão perverso de aplicação da lei, que há séculos assegura a mais ampla impunidade a poderosos de todo gênero, como também um modelo preguiçoso, cruel e ineficiente de capitalismo que faz do contribuinte, especialmente os mais pobres, as amas de leite de grandes empresários, como Eike Batista, Marcelo e Joesleys, assim como da camarilha que lhes serve dos palácios da República. Assim, as eventuais falhas dessas operações, que devem ser sanadas, não podem colocar em risco os benefícios civilizatórios desse movimento de universalização do governo das leis". En español: "Como era de esperarse, las reacciones de los involucrados, investigados y denunciados ha sido virulenta, cuestionando no sólo la integridad de la operación, sino también sus posibles beneficios para la sociedad. Moralista, selectiva, mesiánica, persecutoria e irresponsable son algunos de los adjetivos atribuidos a las operaciones. En efecto, algunas acciones de los agentes de aplicación de la ley, como divulgación no autorizada, escuchas ilegales, prolongación innecesaria de prisiones procesales, culminando con una oscura participación de un miembro del Ministerio Público en el acuerdo de delación súper premiada de Joesley Batista, no se pueden tolerar. Por eso deben ser anuladas y punir apropiadamente a sus responsables. Debemos, sin embargo, tener mucho cuidado para «no tirar el niño con el agua del baño». El juicio del Mensalão, así como la operación Lava-Jato, con todas sus deficiencias van imponiendo a trancas y barrancas, un nuevo paradigma en la conducción de los negocios públicos en el país. Su índole disruptiva viene colocando en jaque no sólo el patrón perverso de aplicación de la ley que desde hace siglos asegura la más amplia impunidad a poderosos de todo género, sino también un modelo perezoso, cruel e ineficiente de capitalismo que hace del contribuyente, especialmente los más pobres, las amas de leche de grandes empresarios, como Eike Batista, Marcelo y Joesleys, así como de la camarilla que les sirve desde los palacios de la República. Así, potenciales fallas de estas operaciones, que deben ser sanadas, no pueden colocar en riesgo los beneficios civilizatorios de este movimiento de universalización del gobierno de las leyes". Cfr. Vilhena Vieira, Oscar, Folha de S. Paulo, 16/09/2017.

16 En gran parte, a causa de la delación recompensada hecha por varias personas. A partir de estas delaciones ha sido posible conocer todo un submundo del crimen organizado, desconocido por la mayor parte de la población brasileña.

Esta obra está bajo una Licencia Creative Commons

Atribución-NoComercial-SinDerivar 4.0 Internacional, IIJ-UNAM.

Boletín Mexicano de Derecho Comparado, núm. 152, pp. 767-785. 
En los primeros años el sistema funcionó razonablemente y garantizó la gobernabilidad del país, pero, con el paso del tiempo, se reveló una gran mesa de negocios espurios.

Las campañas políticas deben ser repensadas y también su modo de financiación, con mayor participación de la justicia electoral, una combinación que estimule al sector privado a participar en la política sin corromperla, y al sector público a contribuir con una parcela de fondos públicos.

La contabilidad paralela de los partidos políticos y empresas (caja 2) surge para financiar al crimen organizado y a los partidos políticos y no acabará con la simple e ingenua prohibición de la financiación privada, tout court.

El clientelismo y el fisiologismo todavía marcan el escenario brasileño. Es preciso romper con este ciclo vicioso, ampliar y perfeccionar la misión de los agentes fiscalizadores de la República, condenar la corrupción y la impunidad y educar al pueblo para la ciudadanía.

La región sufre con un centralismo autoritario de poder, lo que genera el fenómeno del hiperpresidencialismo o formas de "democracia delegativa". La democratización ha fortalecido la protección de los derechos, aunque sin efectuar reformas institucionales profundas y necesarias para la consolidación del Estado democrático de derecho. La región aún convive con las reminiscencias del legado de los regímenes autoritarios dictatoriales, con una cultura de violencia e impunidad, con la baja densidad de Estados de derecho y con la precaria tradición de respeto a los derechos humanos en el plano nacional. Vean cuántos retos tenemos por delante.

\section{CONCLUSIONES}

Frente a todo lo que hemos expuesto, podemos sintetizar las siguientes evidencias en el cuadro político-partidario examinado y el fenómeno de la corrupción en Brasil:

a) El sistema brasileño combina presidencialismo y representación proporcional de lista abierta. Las reglas políticas vigentes han concurrido a la formación de partidos débiles, con poca capilaridad 
social, baja identidad ideológica y falta de cohesión. Las agremiaciones, en general, son formadas por políticos individualistas, particularistas, personalistas y con histórico de migración partidaria (infidelidad partidaria).

b) El gobierno, por fuerza del régimen, "negocia" con su base de sustentación y con la oposición a cada votación importante. Nuestro sistema electoral no garantiza una buena gobernabilidad (calidad).

c) Entre las reformas políticas se apunta la necesidad de la cláusula de desempeño, la racionalización del pluralismo partidario, la reformulación del sistema de coligación partidaria, la imposición de la fidelidad, entre otras medidas.

d) El Mensalão y la operación "Lava-Jato" son ejemplos elocuentes de corrupción que involucra a miembros del Congreso nacional (políticos electos), partidos políticos, dirigentes de la administración pública, instituciones financieras y empresas privadas.

e) Entre las fallas apuntadas que propician dichos fraudes tenemos: la cantidad excesiva de cargos de comisión (confianza) y su dotación política, el lavado de dinero, el desvío de fondos públicos y la necesidad de una reforma política amplia, entre otras.

f) El fuero privilegiado de los políticos (diputados, senadores y otras autoridades) en el Supremo Tribunal Federal es inadecuado y no responde a la necesidad de celeridad para el juzgamiento de los delitos e infracciones contra la administración pública brasileña, lo que genera impunidad.

g) La financiación de las campañas políticas ha dejado de ser mixto (público y privado) para ser exclusivamente público, sin garantías de que el nuevo sistema contribuya para disminuir la corrupción en Brasil, ya que hace falta una fiscalización efectiva de la Justicia Electoral.

\section{BIBLIOGRAFÍA}

CLève, Clèmerson Merlin y Clève, Ana Carolina de Camargo, "A evolução da fidelidade partidária na jurisprudência do Supremo Tribunal Federal", Revista Fus Navigandi, Teresina, año 20, núm. 4492, 19 de octubre de 2015, disponible en: https://jus.com.br/artigos/43664. 
Limongi, Fernando, "Reforma política: o longo debate", Revista Parlamento e Sociedade, São Paulo, vol. 3, núm.4, 2015.

Nuca, Guilherme de Souza, Princípios Constitucionais Penais e Processuais Penais, 3a. ed., São Paulo, 2013.

Vilhena VieIRA, Oscar, Folha de S. Paulo, 16 de septiembre de 2017. 